\title{
Analyzing the Effectiveness of Online Recruitment: A Case Study on Recruiters of Bangladesh
}

\author{
Nafia Sultana*, Nahida Sultana \\ Lecturer, Business Administration, Bangladesh University, Dhaka, BANGLADESH \\ *E-mail for correspondence: nafia.cubd@gmail.com
}

https://doi.org/10.18034/abr.v7i2.14

\begin{abstract}
At present organizations are becoming more online-dependent while dealing the human resource management activities. Today companies prefer online-recruitment media to attract and pick the best suit from a pool of potential candidates. Some advantages are ensured and some problems, too often faced by the organizations during depending on online recruitment. Addressing the effectiveness of online recruitment and generating the solutions for overcoming the current difficulties of online recruitment is key focus of our study. Some variables are identified to evaluate the usefulness of online recruitment to the recruiting organizations. Both primary and secondary are data has been considered for the study. One sample t-test has been conducted to assess the primary data. The study not only identified the efficacy of online recruitment but also discover the stage of recruitment in which organizations get more benefits through using the internet.
\end{abstract}

Key words: Online recruiters, Recruiters, Effectiveness, Perceived Advantage, Bangladesh

\section{INTRODUCTION}

One of the challenges of any organization is to recruit the best workforce from a large pool of applicants. The prospect of a successful company does not only depend on the financial return but also depends on how the organization combines and develops its' human capital. Recruitment is considered as an important part of human resource (HR) management since it executes the vital function of bringing the most significant resource -human capital into the organization" (Barber, 1998). Due to globalization and technological advancement, nowadays corporations rely on online to recruit the best manpower. Even in the developing countries like Bangladesh online-recruitment is getting preference over the conventional recruitment method.

Online recruitment typically specifies the use of technological knowledge and web-based capitals for inviting, screening, cross-examining and choosing the best candidates. Organizations prefer online-recruitment to reach a diverse pool candidate with less cost and time to reduce workload. Khan et.al., (2013) stated online recruitment as a media of bringing effectiveness and efficiency for the employers in finding the right candidates for the right positions. Hence, the focus of the study is to analyze the effectiveness of online recruitment for the recruiters of Bangladesh by developing a model which shows different dimensions of online recruitment including online recruitment media preference, perceived advantage, and improvement in several stages of recruitment.

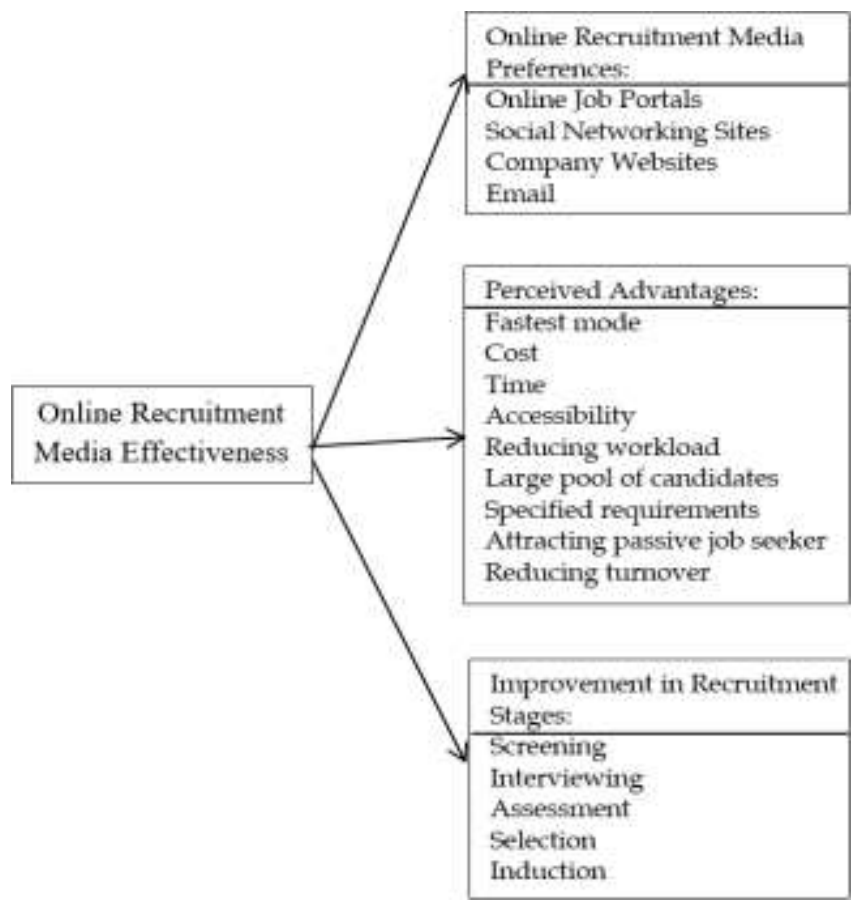

Figure 1: Research Model 


\section{Objectives of the study}

The broad purpose of this study is to analyze the effectiveness of online recruitment to recruiters.

Specific purposes of the study are:

- To identify the preference of online recruitment media

- To explore the perceived advantages of online recruitment

- To assess the improvement of recruitment process

- To find out the problems recruiters face and generate solutions

\section{Research implication}

This study will provide the recruiters a view of the full benefit of online recruitment practice in Bangladesh. Before making a job advertisement, recruiters consider some recruitment media to place the ad. The new business entrants will receive a recommendation from the study about the online recruitment effectiveness in present days of Bangladesh. The recruiting companies will be able to know what recruitment process has been improved and what hasn't been. In Bangladesh, the most improved stage is screening stage. So, the recruiters can undertake steps for making other recruitment stages more improved and efficient.

Along with this, when the human resource department will desire to make new policy for improving the recruitment stages, this study is supposed to guide them showing which stage needs to be focused more and what problems are generally faced by the employers. Some generated solutions may guide the new policy making as well.

\section{Limitations}

The study is based on a limited survey where the survey is conducted on the recruiters of a few industries of Bangladesh. There are many more industries like Banking, Fast Moving Consumer Goods (FMCG) sectors where the practice of online recruitment is established. The viewpoints of the recruiters of these industries have been overlooked here.

\section{LITERATURE REVIEW}

Organizations' investment at the job portal and career content on the website can be beneficial in the long run (Khan, Awang \& Ghouri, 2013). A significant proportion of recruiting companies adopting online recruitment. The companies are considering the online recruitment as an effective method in future making a rising trend in its total use (Parry \& Tyson, 2008). Parry \& Tyson (2008) provided insights into the practice and potential accomplishment of online recruitment systems.

Harris (2005) described online recruitment approaches: we-find-you approach and you-find-us approach wherein we-find-us approach, recruiters search for applicants on job boards and companies' career websites, and in youfind-us approach, recruiters place job advertisements enabling job applicants to apply. Online recruitment provides the benefit of reaching a wider audience of both active as well as passive job applicants. Through we-findyou approach, passive job applicants can easily be found (Carter, 2001 and Haudof \& Duncan, 2004).

Veger (2006) discussed different methods of online recruitment and their benefits in increasing recruitment performance. The process of employment has been radically changed through internet practiced by small and large organizations. Such online recruitment has become a favored medium of both job applicants, and recruiters as the internet are providing the job matching services so cheaply (Kuhn, 2000). Parry\& Wilson (2009) have revealed reasons of a company's decision to practice online recruitment. The factors to adoption of a corporate website and commercial job portals are found different. Human resource managers are less likely to use online recruitment method when they perceive the corporate website use for recruitment negatively (Parry\& Wilson, 2009). Although Parry\& Wilson (2009) found the relative advantage of using online recruitment less significant, Arthur (2001) have argued that cost and time saving are usually related to the use of online recruitment. Galanki (2002) identified factors that affect the recruiting organizations on the decision to recruit through online. Cost-effectiveness and a higher rate of response affect companies to recruit through online. Another influencing factor to their decision includes access to the passive job applicants (Galanki, 2002). He also disputed that the least important factors to recruiters include worldwide coverage and quality of response. The most significant factor is subjective norms that denote those companies where both the employees and employers tend to be online-centric are more likely to use online recruitment (Parry\& Wilson, 2009). Islam (2016) has revealed that the effectiveness of online recruitment depends on the performance, reliability, security and cost-effectiveness.

Although the internet reaches people from broad geographical and social contexts over advertising in single provincial or national newspaper, this also ensures the likelihood to better notify the job seekers about the job description. The extended word limit of online job postings enables a company to communicate accurate job information with prospective contenders letting them self- screening and reducing unfit candidates (Galanaki, 2002). An advantage of Social Networking Sites (SNS) is that they provide the recruiter with an opportunity to attract and approach 'Passive' candidates. Passive candidates generate and maintain professional profile like active job seekers as they suppose that this can bring them closer to the recruiter although they are not actively seeking for a job (Nikoloau, 2014).

One of the most common applications of the internet in HRM activities includes online recruitment and selection. Online advertisement with interactive as well as rich multimedia content can attract the targeted users effectively. Additionally, screening and testing through 
internet support an organization in its recruitment efforts (Ngai et al., 2007). Online pre-screening tools facilitate the organizations to automatically filter out the fit applications from a large number of applications based on the self- administered tests. Fully integrated and online recruitment system can reduce the administrative burdens and simplify the induction process (Barbar, 2006).

Among other sources of recruitment, online recruitment is the most favorite source, and its effectiveness depends on the advertisement placement. As the internet is extensively used by the job applicants, organizations should invest to the establishment of e-recruitment infrastructure that is economically sound as compared to traditional approaches (Khan, Awang \& Ghouri, 2013).

Some papers by different authors have been found about the online recruitment effectiveness. But there is insufficient study found about the perceived advantages of online recruitment and improvement in the recruitment process of a developing country like- Bangladesh. This is the research gap of the study. Through analyzing different papers and present perspective recruiters, variables are taken into consideration. To explore the perceived advantage, the variables that are considered include fastest mode, cost, time, accessibility, reducing workload, large pool of candidates, specified requirements, attracting passive job seeker, reducing turnover, and increasing organizational performance and to assess the improvement of each stage of recruitment process, the test variables that are considered include screening, interviewing, assessment, selection, and induction.

\section{Research Methodology}

\section{Sampling Method}

The convenient random sampling method was applied to select the respondents. Recruiters of different business industries who use online recruitment media for both posting vacancy advertisement and screening potential candidates were selected as the desired sample.

\section{Data collection method}

A structured questionnaire has been prepared for primary data collection. There were about 100 questionnaires were sent, and 35 completed questionnaires were returned with the response rate of $35 \%$. Of them, there are recruiters from different business organizations of Bangladesh.

\section{Analytical tool}

The study is quantitative in manner. The statistical model that best fit with the study is one sample t-test as different variables are identified and analyzed by a specific mean (3) that denote the agreement of different Likert scale statements.

\section{Respondents' information}

There is the participation of different types of respondents to validate the data. The respondents were the recruiters or the HR persons who are related to recruitment from different companies. About $70 \%$ of the respondents have more than ten years' experience. There were 35 respondents from 10 companies, and institutions. The sample characteristics are presented below:

Table 1: Sample Information

\begin{tabular}{|c|c|c|}
\hline Name of company & $\begin{array}{l}\text { Number of } \\
\text { respondents }\end{array}$ & Holding position \\
\hline 1. Robi Axiata Limited & 10 & $\begin{array}{l}5 \text { Vice-Presidents and } \\
5 \text { General Managers }\end{array}$ \\
\hline 2. Partex Star Group & 4 & $\begin{array}{l}2 \text { HR Managers and } 2 \\
\text { Senior Managers }\end{array}$ \\
\hline 3. University of Dhaka & 3 & 3 Professors \\
\hline $\begin{array}{l}\text { 4. } \begin{array}{l}\text { Bangladesh } \\
\text { University }\end{array}\end{array}$ & 3 & $\begin{array}{l}1 \text { Professor, } 1 \text { Registrar } \\
\text { and } 1 \mathrm{HR} \text { manager }\end{array}$ \\
\hline $\begin{array}{l}\text { 5. International Leasing } \\
\text { 6. and Financial } \\
\text { Services } \\
\end{array}$ & 3 & $\begin{array}{l}1 \text { Executive director } \\
\text { and } 2 \text { Senior Managers }\end{array}$ \\
\hline $\begin{array}{l}\text { 7. Islamic Finance and } \\
\text { 8. Investment Limited }\end{array}$ & 3 & $\begin{array}{l}1 \text { Director and } 2 \text { Senior } \\
\text { Managers }\end{array}$ \\
\hline 9. Edison & 3 & $\begin{array}{l}1 \text { SHR Manager and } 2 \\
\text { Senior Managers }\end{array}$ \\
\hline 10. ACI & 3 & $\begin{array}{l}2 \text { Senior executives } \\
\text { and } 1 \text { SHR Manager }\end{array}$ \\
\hline 11. Edoco Group & 2 & 2 HR Managers \\
\hline 12. Binary Pi & 1 & CEO \\
\hline
\end{tabular}

\section{Data AnALYsis}

\section{Preference of online recruitment among recruiters}

The recruiters are asked about the preference of different recruitment media while recruiting. Following chart shows the result:

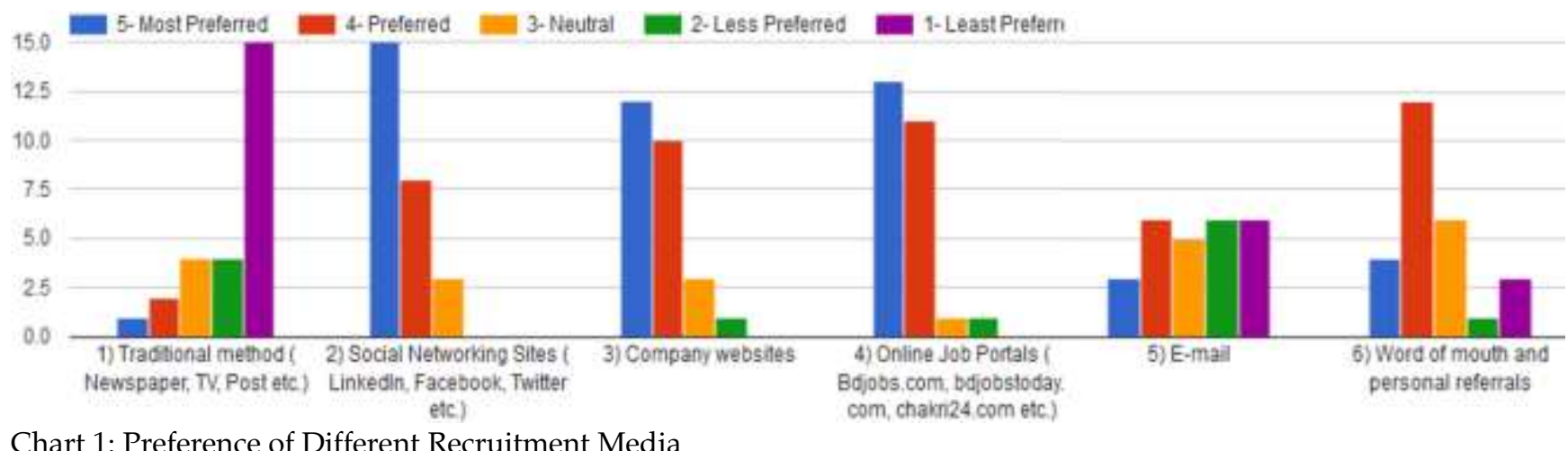

Chart 1: Preference of Different Recruitment Media 
This is observed that a large proportion $(51 \%)$ of recruiters prefer social networking sites, about $42 \%$ recruiters prefer company websites and $46 \%$ of the recruiters prefer online job portals as recruitment media. Some significant proportion prefers the word of mouth and personal referrals as effective recruitment media. There is very a trivial percentage that prefers traditional recruitment media.
The effectiveness of online recruitment has been analyzed in terms following ten factors: fastest mode, cost, time, accessibility, reducing workload, large candidates, filling specified requirements, attracting passive job seeker, reducing turnover and increasing organizational performance. All factors have been analyzed with test value three as each of the questions was Likert- scale question.

\section{Perceived advantages of online recruitment}

Table 2: Advantages of Online Recruitment (One sample t- test)

\begin{tabular}{|l|c|c|c|c|c|c|}
\hline & $\mathrm{t}$ & $\mathrm{df}$ & Sig. (2-tailed) & \multirow{2}{*}{ Mean Difference } & \multicolumn{2}{|c|}{ 95\% Confidence Interval of the Difference } \\
\cline { 7 - 7 } & & & & & Lower & Upper \\
\hline Fastest mode & 8.395 & 34 & .000 & 1.25714 & .9528 & 1.5615 \\
\hline Cost & 15.938 & 34 & .000 & 1.51429 & 1.3212 & 1.7074 \\
\hline Time & 11.926 & 34 & .000 & 1.40000 & 1.1614 & 1.6386 \\
\hline Accessibility & 14.113 & 34 & .000 & 1.45714 & 1.2473 & 1.6670 \\
\hline Reducing workload & 7.781 & 34 & .000 & 1.17143 & .8655 & 1.4774 \\
\hline Large pool of candidates & 13.899 & 34 & .000 & 1.42857 & 1.2197 & 1.6375 \\
\hline Specified requirements & 6.655 & 34 & .000 & .94286 & .6549 & 1.2308 \\
\hline Attracting passive job seeker & 7.483 & 34 & .000 & .80000 & .5827 & 1.0173 \\
\hline Reducing turnover & .495 & 34 & .624 & .05714 & -.1777 & .2919 \\
\hline $\begin{array}{l}\text { Increasing organizational } \\
\text { performance }\end{array}$ & 5.351 & 34 & .000 & .68571 & .4253 & .9461 \\
\hline
\end{tabular}

The significant variables of online recruitment effectiveness include fastest mode, cost, time, and accessibility, reducing workload, reach to large candidates, filling specified requirements, attracting passive job seeker and increasing organizational performance as the p-value is smaller than .05. Recruiters find the effectiveness of online recruitment mostly regarding cost saving, followed by accessibility, large candidates and time-saving. Least significant factors are attracting passive job seekers, and increasing organizational performance. The insignificant factor is reducing turnover $(\mathrm{t}=.273[\mathrm{df}=26], \mathrm{p}>.05)$.

\section{Improvement of recruitment process}

There are five stages of the recruitment process identified including screening, interviewing, assessment, selection, and induction. The respondents have been asked five Likert-scale questions about the improvement in different recruitment processes. Data has been analyzed with one sample t-test with test value 3 .

This is observed that; on average, the recruitment processes that have been improved through online recruitment include screening, interviewing and assessment as their P-value is smaller than .05. Screening is found to be improved most, followed by assessment and interviewing. Selection and induction $(\mathrm{t}=1.308$ [df=26], $\mathrm{p}>.05$ and $(\mathrm{t}=.493$ [df=26], $\mathrm{p}>.05$ respectively) are not improved by online recruitment system.

Table 3: Improvement in each Recruitment Stages (One sample t- test)

\begin{tabular}{|l|c|c|c|c|c|c|}
\hline & $\mathrm{t}$ & $\mathrm{df}$ & Sig. (2-ailed) & \multirow{2}{*}{ Mean Difference } & \multicolumn{2}{|c|}{ 95\% Confidence Interval of the Difference } \\
\cline { 6 - 7 } & & & & & Lower & Upper \\
\hline Screening & 10.539 & 34 & .000 & 1.22857 & .9917 & .4655 \\
\hline Interviewing & 2.606 & 34 & .013 & .37143 & .0818 & .6611 \\
\hline Assessment & 3.311 & 34 & .002 & .45714 & .1765 & .7377 \\
\hline Selection & .442 & 34 & .661 & .05714 & -.2056 & .3199 \\
\hline Induction & .215 & 34 & .831 & .02857 & -.2412 & .2984 \\
\hline
\end{tabular}

\section{Discussion}

Graphical illustration revealed a generic perception of recruiters about the recruitment media preference. It is seen that online recruitment media - Online Job Portals, Company Websites, Social Networking Sites, and Emails are most preferred among the recruiters. Very insignificant percentage of recruiters thinks that traditional media, word-of-mouth and referrals can be considered as the effective mean of recruitment.

Speed, cost, time, accessibility, reducing workload, reaching to a large pool of candidates, meeting specified requirements, attracting passive job seeker and increasing organizational performance have been found significant factors that provide advantages to employers. The 
effectiveness of online recruitment is found mostly regarding cost saving, followed by accessibility, reaching to large candidates and time-saving. It is also noticeable that the recruitment stage improved most by online is screening followed by assessment, and interviewing. Many more problems are identified by the recruiters and certain solutions have been generated accordingly.

\section{Summary of findings}

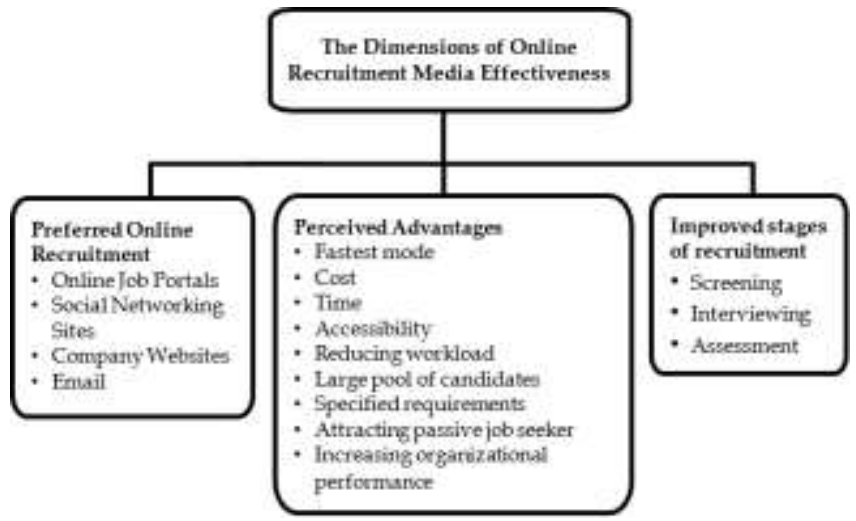

Figure 2: Results of the study

\section{Suggestions by respondents}

The respondents were asked to identify what recruitment media they prefer for urgent recruitment. A very few respondents opined that online recruitment is the best. Most of the respondents think that using online recruitment media is okay for the time being, but it needs to be improved. Many respondents argue that there is lack of personal interaction while using online recruitment media. The problem that is stated most by the respondents is the applicants often do not provide authentic information. Again, the respondents feel that online recruitment takes much time to pick the best candidates for interview from a broad pool of applicants. Sometimes candidates apply for positions that do not suit their qualifications which may lead to consumption of time of the recruiters.

The respondents suggested a few ways to overcome the problems. They think there should be an automated filtration tool to screen the application without much time and effort. Some also suggest introducing Skype interview to advance all stages of recruitment.

\section{RECOMMENDATIONS}

Some recommendations have been proposed after analyzing the fact and findings here:

- The online recruitment media should advance their tools by providing some auto-filtration techniques so that perfect candidates can be chosen quickly and easily.

- The organizations should practice the use of online recruitment in all stages of recruitment process.

- There should be a clear feedback system between the recruiters and applicants while using online media of recruitment.

\section{CONCLUSION}

Many of the organizations are becoming online-centric day by day. So, this is necessary for the new entrants to understand the effectiveness of online recruitment regarding different dimensions. The study focused on showing the effectiveness of online recruitment in terms of preference of different media among employers, perceived advantages as well as improvement in different recruitment stages. This is observed that very insignificant number of recruiters prefer traditional media, word of mouth and referrals for employee recruitment. The perceived advantage analysis showed that online recruitment is effective regarding speed, cost, time, and accessibility, reducing workload, reaching to a large pool of candidates, meeting specified requirements, attracting passive job seeker and increasing organizational performance. Another finding presented that the recruitment has been improved most in the screening stage. So, the organizations should be concerned about how they can utilize the benefits of online recruitment in other stages of the recruitment process to make the recruitment process easy, flexible and convenient. They should undertake proper steps to solve the faced problems in recruitment process.

In future, researchers can further work on proposing a system to accelerate the online recruitment effectiveness in other recruitment stages, and to do investigate whether online recruitment is filling the gap between recruiters and job seekers.

\section{REFERENCES}

Arthur, D. (2001). The employee recruitment and retention handbook. New York: AMACOM Div American Mgmt Assn.

Awang, M. G. (2013). Impact of E-Recruitment and Job-Seekers Perception on Intention to Pursue the Jobs. Management $\mathcal{E}$ Marketing - Craiova, Vol. 11, pp. 47-57.

Barber, L. (2006). E-recruitment Developments. Brighton: Brighton: Institute for Employment Studies.

Cober, R. T. (2004). Recruitment on the Net: How Do Organizational Web Site Characteristics Influence Applicant Attraction? Journal of Management, Vol. 30, pp. 623-646.

Galanaki, E. (2002). The decision to recruit online: a descriptive study. Career Development International, Vol. 7, pp. 243-251.

Hausdorf, P. A. (2004). Firm Size and Internet Recruiting in Canada: A Preliminary Investigation. Journal of Small Business Management, Vol. 42, pp. 325-334.

Islam, M. M. (2016). Analysis of E-recruitment Trend and Effectiveness:. Business Management, Vol. 30 pp. 1-2.

Kuhn, P. (2000). Policies for an internet labour market. Policy Options-Montreal , Vol.21, pp.42-47.

Ngai, E. L. (2007). Importance of the internet to human resource practitioners in Hong Kong. Personnel Review , 37(1), pp.66-84.

Nikolaou, I. (2014). Social networking web sites in job search and employee recruitment. International Journal of Selection and Assessment , Vol. 22, pp.179-189. 
Parry, E. \&. Tyson, S. (2008). An analysis of the use and success of online recruitment methods in the UK. Human Resource Management Journal, Vol. 18, pp. 257-274.

Parry, E. \&. Wilson, H. (2009). Factors influencing the adoption of online recruitment. Personnel Review , Vol. 38, pp.655-673.
Veger, M. (2006). How does Internet recruitment have effect on recruitment performance? In Fourth Twente Student Conference on IT , Vol. 30.

Online Archive: $\underline{\text { https://abc.us.org/ojs/index.php/abr/issue/archive }}$ 